\title{
The effeect of entrepreneurship on organizational excellence: The mediating role of visionary leadership
}

\section{Ghufran Saed Hijjawi ${ }^{a^{*}}$}

${ }^{a}$ Business and Finance Faculty, The World Islamic Science and Education University (WISE), P.O Box 1101, Postal Code 11947, Amman, Jordan

\section{H R O N I C L E}

\section{Article history:}

Received: July 7, 2020

Received in revised format:

August 102020

Accepted: August 17, 2020

Available online:

August 25, 2020

Keywords:

Entrepreneurship

Organizational Excellence

Visionary Leadership

Jordan Commercial Bank

West Bank

Jordan

\section{A B S T R A C T}

\begin{abstract}
Entrepreneurship is vital for enhancing an organization position among its rivals and may establish new opportunities. The positive effects of entrepreneurship are realized, however, if the business environment is receptive to innovation; especially the internal environment within its leadership, it can act as a motivator for it. This study aimed to identify the impact of entrepreneurship on organizational excellence through the mediating role of visionary leadership, where the study population was the managers at different levels in the Jordan commercial bank. A random sample was used to collect data from (54) branch distributed between Jordan and West Bank, where the sample consisted of (183) distributed questionnaires, while the valid questionnaires for statistical analysis were (154), which is reflected a responding rate of $(84.15 \%)$ of distributed questionnaires. Structural Equation Modeling (SEM) was applied as a statistical method to attain the study objectives and testing its hypotheses. The study results indicated that entrepreneurship with its dimensions (innovativeness, pro-activeness, risk-taking, and aggressive competition) had a significant impact on both visionary leadership and organizational excellence, also visionary leadership had a significant impact on organizational excellence, while the mediating test referred that the visionary leadership played a partial mediating role between entrepreneurship and organizational excellence. Consequently, the study concluded that external and internal environments could act as a motivator for entrepreneurship and consequently for achieving organizational excellence through having visionary leadership and flexible structures and policies.
\end{abstract}

\section{Introduction}

Business organizations faced everyday with increased and accelerated turbulence and changing in global environment, most of these changes are according to customers who expect more, become less loyal for specific brands since they have more choices; therefore, thinking in building sustained approach for development become essential to be able to achieve long-term and sustain success called "organizational excellence". Organizational excellence is built through achieving alignment between all the systems in organization to deliver and fulfill all needs and expectations of all stakeholders, this content is similar to the term called "quality of an organization" built on self-assessment and be known from (ISO 9004; 2018). The importance of organizational excellence is highlighted by giving the organization a qualitative, quantitative and preferential superiority over competitors, as it makes the organization superior in its performance and in providing service together, as it contributes to a positive impact on the perceptions of workers and customers, and stimulates them for continuous development, which contributes to their long-term continuity. Organizational excellence is the development of plans to achieve organizational prosperity, which is consistent with the organization and its environment (Hadi et al., 2019). Currently, the concerns about increasing unemployment through youth due to different causes such as: global economic crises and long term economic depression, along with intention toward downsizing to save cost mainly man power cost, make this problem grows and push

* Corresponding author.

E-mail address: Gh hijawi@hotmail.com (G. S. Hijjawi) 
the governments to think seriously how to solve. Spreading and encouraging entrepreneurship spirit between youth is the solution to create new businesses, ideas, processes, approaches and be able to get or create new markets.

Visionary Leadership leaders need to help organizations develop a greater sense of organization's goal by linking efforts to successful outcomes. Visionary and empowering leadership appear to be particularly suitable to meet key demands arising from the contexts within which many organizations are embedded (Kearney et al., 2019). Visionary leaders develop their own personal vision then merge it into a shared vision with their colleagues (Taylor et al., 2014). A study by Samawi et al., (2018) confirmed that leadership does have a strong positive influence on organizational excellence in service firms in the private sector in Jordan. According to Zhu et al. (2005), visionary leadership creates high levels of cohesion, commitment, trust, motivation, and enhanced performance in the new organizations. Under visionary leadership, individuals are encouraged to participate in teams of cooperative behavior and to make more contributions to achieve organizational goals (Zhou et al., 2018). Despite the fact that this research study has made significant contributions at both theoretical and practical levels, by reviewing the theoretical literature related to the study variables, the researcher found that there are no studies that link entrepreneurship with organizational excellence, especially in the presence of the visionary leadership variable as a mediator variable, and therefore, the important contribution of this research to the banking literature is to determine the importance of visionary leadership in the relationships between entrepreneurship and organizational excellence since there are very limited studies that have taken visionary leadership into consideration in the bank sector, especially in a developing country like Jordan. Furthermore, the findings of this study could help the decision makers at private sectors when they intend to improve their performance by focusing on entrepreneurship. This study examines the mediating effect of visionary leadership on the relationship between entrepreneurship and organizational excellence.

\section{Theoretical Framework}

\subsection{Entrepreneurship}

Entrepreneurship is a key indicator of social, technological, and economic growth. Entrepreneurs are considered as one of the countries' growth driver as they provide to their countries the latest cultural, organizational, and technological advancement from the global world (Gaddam, 2008). Consequently, many governments have continued to make attempts to promote their people to engage in entrepreneurship activities, as well as attracting entrepreneurs to their countries through a set of policies which motivated to increased creativity projects (Genc et al., 2019). Entrepreneurship is not restricted to a variety of practices which organizations are taking advantage of to provide their clients with different ranges of products or services. Rather, it is recognized as an approach focused on the theoretical and empirical principles that the organization can use to gain a sustainable competitive advantage and achieve its objectives in effective and efficient ways (Frederick et al., 2019).

Akbar (2016) defined entrepreneurship as the organization's strategy based on accepting the risks associated with providing innovative products and services, and Olannye and Eromafuru (2016) referred it as the mechanism that the organization's value is created by exploiting the unique and acquired set of resources to seize the opportunities available in the business environment, while Karim (2016) has argued that entrepreneurship is represented by two elements of the capabilities necessary to organize and develop a specific idea and the desire to accomplish this goal, despite the presence of potential risks that may hinder access to the planned results. Consequently, entrepreneurship is considered as one of the management concepts with dynamic characteristics since it is closely related to monitoring the changes that get on the needs and desires of customers and meeting them by creating novel products and services that precede the competitors' orientation for this, despite the uncertainty in the ability of these products and services to meet the aspirations of customers.

\subsubsection{Elements of Entrepreneurship}

Researchers in managerial and strategic sciences in organizations have pointed out widely that entrepreneurship can be measured through four dimensions which are innovativeness, pro-activeness, risk-taking and aggressive competition (Antonites \& Nonyane-Mathebula, 2012; Bedoya et al., 2018; De Oliveira et al., 2016; Gathungu et al., 2014; Salamzadeh et al., 2019). Therefore, in this study, these dimensions were adopted to measure entrepreneurship at Jordan Commercial Bank, where they can be discussed as follows:

Innovativeness: is considered the critical element for entrepreneurship, as it indicates the organization's activity towards adopting new ideas in order to achieve a competitive advantage (Shepherd \& Wiklund, 2020), while Haider et al., (2017) considered it as a business chain aimed at providing new services and products or developing business models that help to cope with threats in the business environment and seizing the opportunities that enhance the organization's position among competitors and enable it to satisfy customer desires.

Pro-activeness: the circumstances of the volatile business environment led to the constant changing of the needs and desires of customers (Dvouletý, 2017). Pro-activeness is seen as the seeking of organizations to meet the needs and desires of customers by developing and providing new products and services before competitors (Dana \& Ratten, 2017), as well as referred by Dzomonda et al., (2017) as the organization's endeavor to predict and exploit business opportunities quickly to cope with the desires of its customers in a way that precedes competitors. 
Risk-taking: the commencement of any work planned by organizations carries with it a different percentage of risks (Das \& Joshi, 2007). Xaba and Malindi (2010) believe that bearing risks is one of the characteristics of entrepreneurs, as it enables them to take audacious decisions to enter into new businesses or markets, while Sozuer et al., (2017) considered the managers' tendency to deal with the changing business environment conditions by taking exceptional decisions related to directing the organization's resources towards exploiting opportunities with uncertain results.

Aggressive competition: is a term towards to direct confrontation with competitors rather than avoiding them through competition strategies that achieve the best services and products at appropriate prices for customers (Salamzadeh et al., 2019). Bedoya et al. (2018) argued that aggressive competition is one of the obstacles that organizations make to avoid new organizations entering the industrial sector in which they work, thus helps them maintain the market share that they acquired.

\subsection{Organizational Excellence}

When talking about organizational excellence, it is necessary to point out two important aspects, which are identifying the stakeholders "customers, workers, suppliers, and marketers" and the other side is managing the basic processes of "developing a new product, attracting customers, reducing costs, and meeting needs" and organizational excellence is closely related to the quality of work performed by the worker, and the social behavior that is called organizational citizenship behavior, there are several factors that must meet in the organization for its distinct performance, including: clarity of the organization's goals, commitment of all levels of leadership to a process of improvement and development, leaders 'possession of a high level of capabilities, skills and innovation. There are various definitions and opinions about organizational excellence that vary according to development of number of excellence models. Golmohammadi et al. (2016) defined organizational excellence as an organizational commitment to sustainable development through the improvement of organizational culture, the working environment and human resources. According to Webster (2016), organizational excellence is sustained delivery of outstanding value to all key stakeholders. According to ASQ (2015), organizational excellence is establishing internal framework for standards and processes that motivate employees to deliver processes, products or services that satisfy customer requirements within business expectations. According to European Foundation for Quality Management (EFQM, 2012), excellent organizations are those organizations that deliver outstanding sustained performance levels that meet or exceed expectations of stakeholders. Thus, organizational excellence is a result or outcome of collaboration and teamwork efforts. From many studies and researches, it is obvious that there are critical keys for organizational success such as customer focus orientation, personnel quality and innovation (Best, 2004; Drucker, 2001; Kotler, 2003; Wing, 1988), The findings of the above studies are consistent with the organizational excellence factors presented by (Darling \& Nurmi,1995). According to other study (Shelton, Darling \& Walker, 2002: 49; Mahalli, 2013) organizational excellence has three dimensions, which are leadership excellence, excellence in service delivery, and excellence in operation management. From (EFQM, 2013) organizational excellence can be viewed from four dimensions: business excellence (results), society excellence, customer excellence, and quality of human resources. Finally; (the model of King Abdullah's award for organizational excellence, 2014) defined organizational excellence through human resources excellence, strategies and policies excellence, organizational structure excellence, organizational culture excellence, leadership excellence. This model dimension is being used in this study since it is the most popular one for Jordanian organizations. Organizational excellence is an intellectual pattern and management philosophy based on a specific approach that relates to how to achieve solid and strong outcomes for organization to achieve a balance in satisfying the needs of all parties, within a culture of learning, creativity and continuous improvement (Alozi et al., 2017).

\subsection{Visionary Leadership}

Leadership is important element in any organization to make change and develop, it is essential element for any success and growth. (Northouse, 2013) defined leadership as a process where an individual attempt to influence others to achieve their common goal. Leaders are role models who shape the future and make it happen by creating vision, mission, and values and inspire others to act according to them by spreading trust through members and through engagement with different stakeholders (EFQM, 2013). Visionary leadership, a form of transformational leadership, offers opportunities to foster the capacity of an organization to meet the needs of its constituents (Taylor et al., 2014). These Visionary leaders are effective in different types of organizations: religious, government, business, sports, etc. They focus on communicating their missions and visions to get sustainable performance through inspiring subordinates (Dhammika, 2016). Taylor (2013) points out that visionary leaders inspired toward organizational interests rather self-interest. Commitment, trust and loyalty are created through achieving visionary leadership (Nwachukwu et al., 2017)

\subsection{Study Hypotheses}

Based on the above literature the study hypotheses can be formulated as follow:

H0.1: There is no effect of entrepreneurship at a significance level $(\alpha \leq 0.05)$ on organizational excellence in Jordan commercial bank.

H0.2: There is no effect of entrepreneurship at a significance level $(\alpha \leq 0.05)$ on organizational through visionary leadership in Jordan commercial bank. 


\section{Research Model}

The hypotheses of the study may be supported by the following theoretical framework, shown in Fig. 1

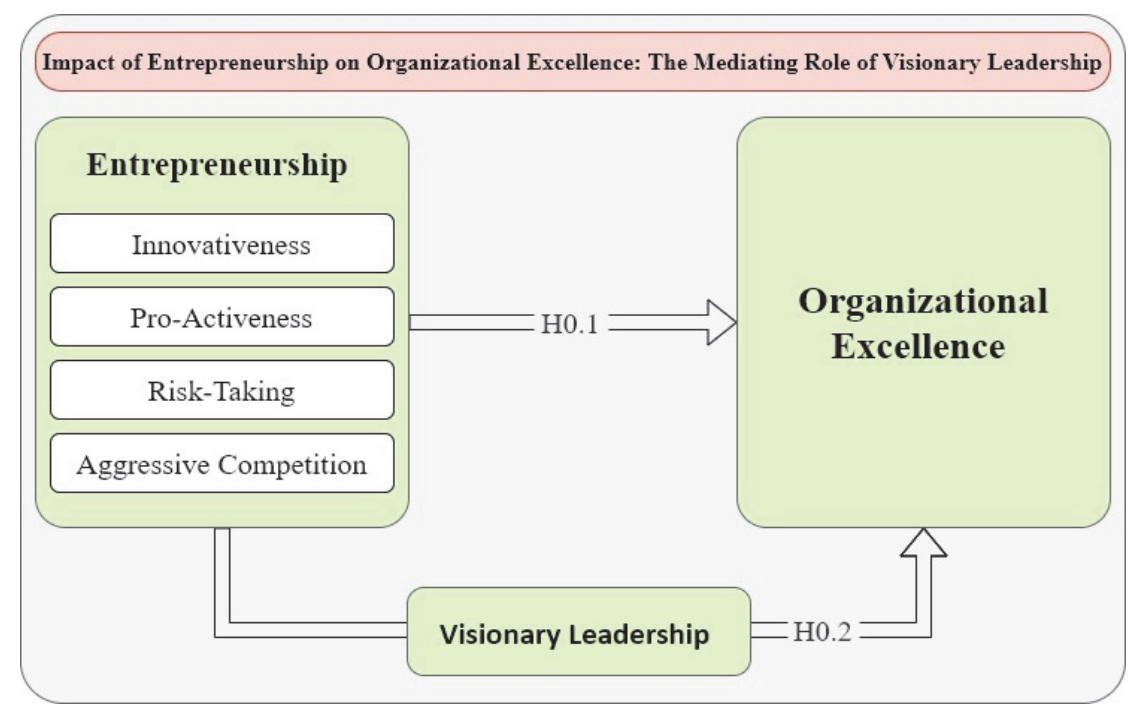

Fig. 1. Research proposed model

\section{Methodology}

To achieve the purpose of the current study, quantitative data related to the study variables of entrepreneurship, organizational excellence and visionary leadership were collected and analyzed using the descriptive approach in order to identify the levels of the variables within the research population, as well as the analytical approach to test the research hypotheses.

\subsection{Research Instrument}

A questionnaire was the major study instrument which is divided into four sections; the first section was related to demographic data about the sample; the second section was used to measure the independent variable, which was entrepreneurship, and its dimensions were innovativeness, pro-activeness, risk-taking, and aggressive competition using 16 items. The third section dealt with the mediating variable of this study, which was visionary leadership that measured by 7 items, while the fourth section designed to measure the dependent variable that was organizational excellence using 21 items. Five points Likert scale was applied for all items in the current study to determine the respondent answer, where the lowest value 1 referred to "Strongly disagree" and the highest value 5 indicated to "Strongly agree".

\subsection{Study Population and Sample}

The population of this study was represented by managers at various administrative levels working in Jordan Commercial Bank as one of the entrepreneurial banks in providing banking services to individual and institutional clients and achieving the goals of stakeholders through 34 branches spread in Jordan and 20 in West Bank. The random sample method was used to collect data from the study population, as the sample size reached (183) distributed questionnaires, while the retrieved and valid questionnaires for statistical analysis reached (154) questionnaires, which represent a response rate $(84.15 \%)$ of the distributed questionnaires. Fig. 2 demonstrated the demographic and functional characteristics of the study sample.

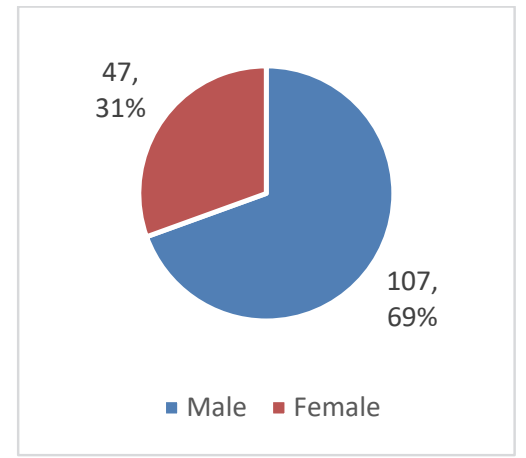

Gender

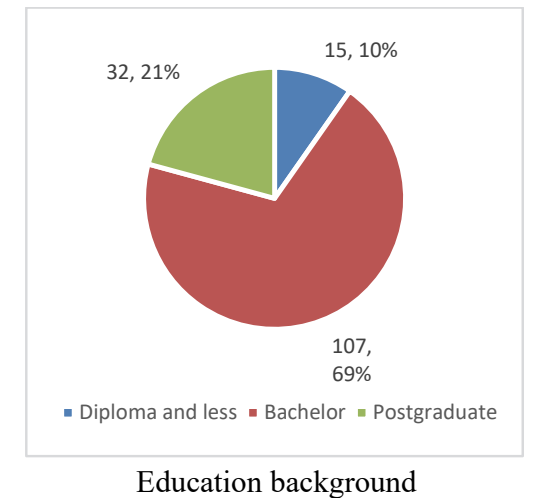

Education background

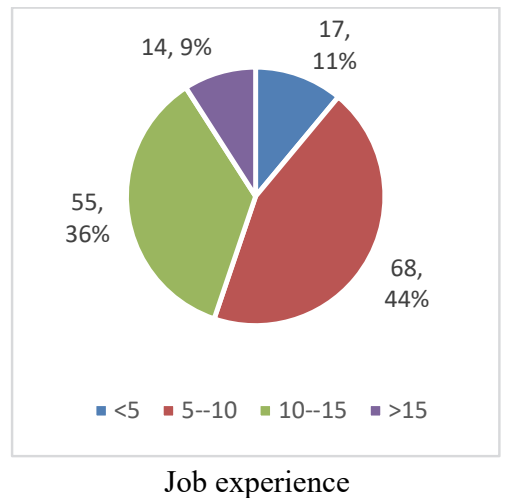

Job experience

Fig. 2. Personal characteristics of the participants 


\subsection{Validity and Reliability}

A set of statistical methods was used in this study to identify the validity and reliability of the instrument that was used to collect data, where convergent validity was determined by the average variance extracted (AVE), and discernment validity was verified by comparing the values of both the maximum shared variance (MSV) and the square root of average variance extracted ( $\sqrt{ } \mathrm{AVE})$ with the calculated value of average variance extracted (AVE). With respect to reliability, the Cronbach's Alpha coefficient (Alpha) was used to measure internal consistency and McDonald's Omega coefficient to verify composite reliability (C.R). The achieved results are presented in Table 1.

Table 1

The results of testing instrument validity and reliability

\begin{tabular}{lcccccc}
\hline & INN & PAC & RTK & ACO & OEX & VLE \\
\hline INN & $\mathbf{0 . 7 1 3}$ & & & & & \\
PAC & 0.315 & $\mathbf{0 . 7 1 1}$ & & & & \\
RTK & 0.428 & 0.305 & $\mathbf{0 . 7 2 2}$ & & & \\
ACO & 0.343 & 0.508 & 0.234 & $\mathbf{0 . 7 1 2}$ & & \\
OEX & 0.186 & 0.451 & 0.428 & 0.438 & $\mathbf{0 . 7 2 2}$ & \\
VLE & 0.637 & 0.227 & 0.615 & 0.351 & 0.539 & 0.816 \\
Loadings Range & $0.70-0.73$ & $0.69-0.75$ & $0.69-0.74$ & $0.70-0.72$ & $0.66-0.76$ & $0.76-0.83$ \\
AVE & 0.508 & 0.505 & 0.521 & 0.507 & 0.503 & 0.505 \\
MSV & 0.433 & 0.346 & 0.462 & 0.310 & 0.513 & 0.398 \\
Alpha & 0.805 & 0.805 & 0.814 & 0.805 & 0.836 & 0.803 \\
C.R. & 0.848 & 0.834 & 0.842 & 0.833 & 0.880 & 0.818 \\
\hline
\end{tabular}

Note: INN: Innovativeness; PAC: Pro-Activeness; RTK: Risk-Taking; ACO: Aggressive Competition; OEX: organizational excellence; VLE: Visionary Leadership; Bold numbers in table indicated to root square of average variance extracted.

The results indicate that all values of item loadings on their latent variables came greater than the threshold of 0.5 for acceptance the item (Al-Hawary \& Al-Namlan, 2018), and the values of the average variance extracted (AVE) were within the range $(0.503-0.665)$, that is greater than the lowest acceptance value of 0.50 , and the values of maximum shared variance (MSV) came smaller than the values of the average variance extracted (AVE), as well as the square root of average variance extracted ( $\sqrt{A V E})$ were higher than the correlation between the rest of the variables, thereby the study instrument can be considered valid (Ab Hamid et al., 2017; Zenk et al., 2019). For the study tool reliability tests, the results listed in Table (2) show that the values of the Cronbach's Alpha coefficient ranged between 0.803 and 0.934 that were greater than 0.70 , the minimum value to judge the internal consistency of the latent variables, as well as the values of McDonald's Omega coefficient was within the range $(0.818-0.936)$ which is greater than 0.80 , the minimum value of the composite reliability (C.R). Accordingly, the study instrument can be reliable (Ahmad et al., 2016; Al-Hawary et al., 2017; Sung et al., 2019).

\section{Data Analysis and Results}

Mean and standard deviation were used as descriptive analysis methods in order to determine the level of entrepreneurship, organizational excellence and visionary leadership in Jordan commercial bank, where the Table 2 illustrate the results obtained through descriptive analysis tests, as well as results of multicollinearity tests between the dimensions of entrepreneurship.

Table 2

The results of descriptive analysis and multicollinearity

\begin{tabular}{lcccc}
\hline & Mean & SD & VIF & Tol. \\
\hline INN & 3.43 & 0.618 & 1.613 & 0.620 \\
PAC & 3.54 & 0.592 & 1.252 & 0.799 \\
RTK & 3.62 & 0.608 & 1.560 & 0.641 \\
ACO & 3.55 & 0.605 & 1.246 & 0.803 \\
OEX & 3.59 & 0.566 & --- & --- \\
VLE & 3.68 & 0.760 & --- & -- \\
\hline
\end{tabular}

Note: INN: Innovativeness; PAC: Pro-Activeness; RTK: Risk-Taking; ACO: Aggressive Competition; OEX: organizational excellence; VLE: Visionary Leadership.

The results of Table 2 indicate a moderate level of entrepreneurship in Jordan Commercial Bank, where the highest mean was for risk-taking $(\mathrm{M}=3.62, \mathrm{SD}=0.608)$, while the lowest mean for the innovativeness $(\mathrm{M}=3.43, \mathrm{SD}=0.618)$. The same applies to organizational excellence, where it referred to a moderate level $(\mathrm{M}=3.59, \mathrm{SD}=0.566)$. On the contrary, the results indicated that visionary leadership was of a high level in Jordan Commercial Bank, where the mean was (3.68) with a standard deviation of (0.760). 
Moreover, the results determined in Table 3 indicate that the dimensions of entrepreneurship are completely free from the problem of multicollinearity, where the values of the variance inflation factor (VIF) ranged between (1.246) and (1.613), that is less than the maximum allowed limit of 3 (Thompson et al., 2017), as well as the tolerance values (Tol.) were within the range (0.620-0.803) which are greater than the lower threshold of 0.1 (Park, 2017). The previous result was emphasized by the values of correlation coefficients between the dimensions of entrepreneurship shown in Table (2) which indicated to correlation values less than 0.80 (Hair et al., 2017). The current study hypotheses were tested using the structural equation modeling (SEM) through the program of (AMOS v24), where the first main hypothesis was that there is no effect of entrepreneurship on organizational excellence and the results came as shown in Table 3.

Table 3

Testing the impact of entrepreneurship on organizational excellence

\begin{tabular}{|c|c|c|c|c|c|c|c|c|c|}
\hline Hypothesis & & Path & & $\mathrm{B}$ & S.E & Beta & $\mathrm{t}$-test & p-value & Result \\
\hline H0.1 & ENT & $\rightarrow$ & OEX & 1.099 & 0.060 & 0.829 & 18.304 & $* * *$ & Rejected \\
\hline
\end{tabular}

Note: ENT: Entrepreneurship; OEX: Organizational Excellence; ${ }^{*} \mathrm{p}<0.05 ; * * \mathrm{p}<0.01 ; * * * \mathrm{p}<0.001$.

Based on the results presented in Table 3, we learn that entrepreneurship has a statistically significant impact on organizational excellence at a level of significance less than 0.05 and this impact was based on the value of the standard beta of (0.829), therefore the null hypothesis was rejected and the alternative hypothesis was accepted. Fig. 3 shows the structural model used to test the first major hypothesis that aims to test the impact of entrepreneurship on organizational excellence.

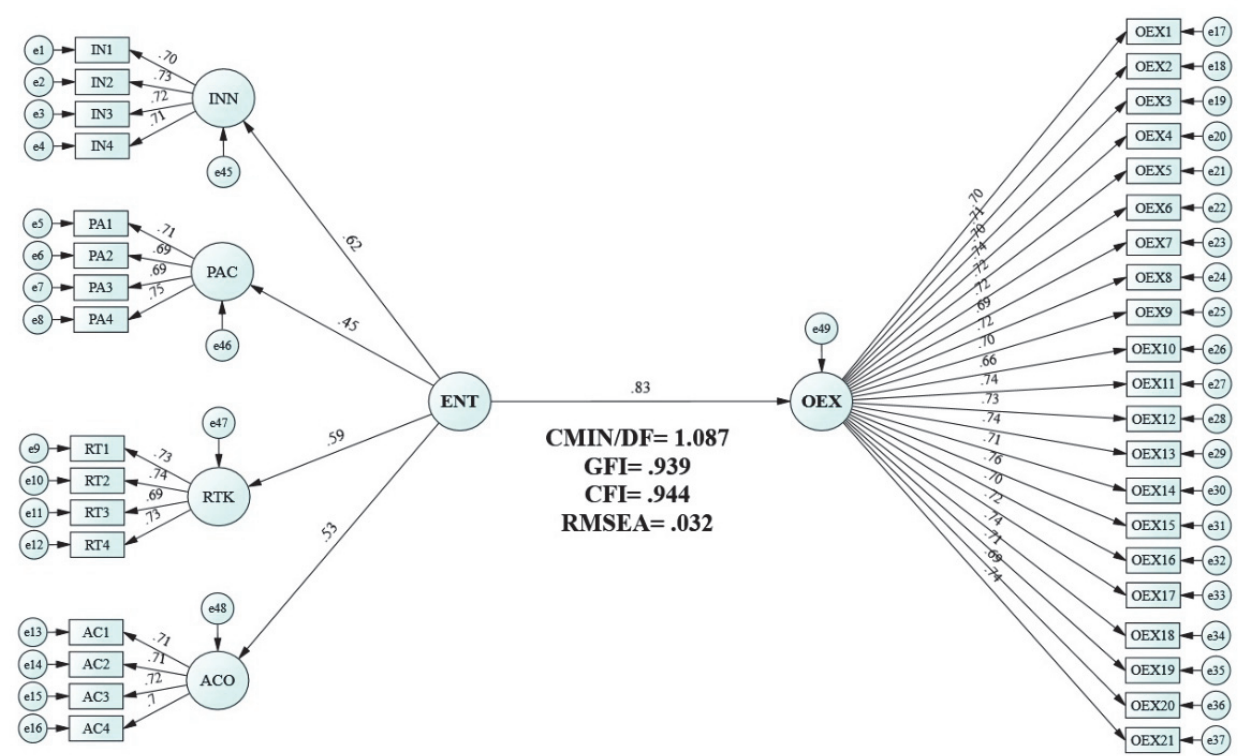

Fig. 3. Structural equation modeling to test the impact of entrepreneurship on organizational excellence

The results shown in Fig. 3 indicate that the values of the goodness of fit indicators of the used model were all acceptable, where the ratio of (CMIN/DF) was (1.087) which is less than the maximum allowed limit 3, as well as the values of (GFI) and (CFI), respectively (0.939) and (0.944) that is greater than 0.90, and the value of (RMSEA) was less than the highest acceptable value of 0.05 , thus the study model used was considered appropriate (Shi et al., 2019). Finally, the second, third and fourth major hypotheses related to the mediate impact of visionary leadership between the relationship of entrepreneurship and organizational excellence were tested through standard direct and indirect impact coefficients, where the results were shown in Table 4.

Table 4 shows that entrepreneurship has a statistically significant impact at the level of significance less than 0.05 on visionary leadership with a value of this direct effect (0.32), and visionary leadership had a statistically significant impact on organizational excellence at a level of significance less than 0.05 with a direct impact value of $(0.46)$, while the mediating role of visionary leadership between entrepreneurship and organizational excellence, the results indicated that there was an indirect effect (0.15) and a direct impact of (0.83) which are statistically significant at a level less than 0.05 . This result indicated that visionary leadership play a partial mediating role between entrepreneurship and organizational excellence. Figure (3) illustrates the structural model for testing the mediating impact of visionary leadership between entrepreneurship and organizational excellence. 
Table 4

Testing the mediating role of visionary leadership between the relationship of entrepreneurship and organizational excellence

\begin{tabular}{crrrcccc}
\hline Hypothesis & & Path & & Direct impact & Indirect impact & Total impact & Result \\
\hline \multirow{3}{*}{ H0.2 } & ENT & $\rightarrow$ & VLE & 0.32 & --- & $0.32 * * *$ & \\
& VLE & $\rightarrow$ & OEX & 0.46 & --- & $0.46^{* * *}$ & Rejected \\
& ENT & $\rightarrow$ & OEX & 0.83 & 0.15 & $0.98^{* * *}$ & \\
\hline
\end{tabular}

Note: ENT: Entrepreneurship; OEX: Organizational Excellence; VL: Visionary Leadership; ${ }^{*} \mathrm{p}<0.05 ;{ }^{* *} \mathrm{p}<0.01 ;{ }^{* * *} \mathrm{p}<0.001$.

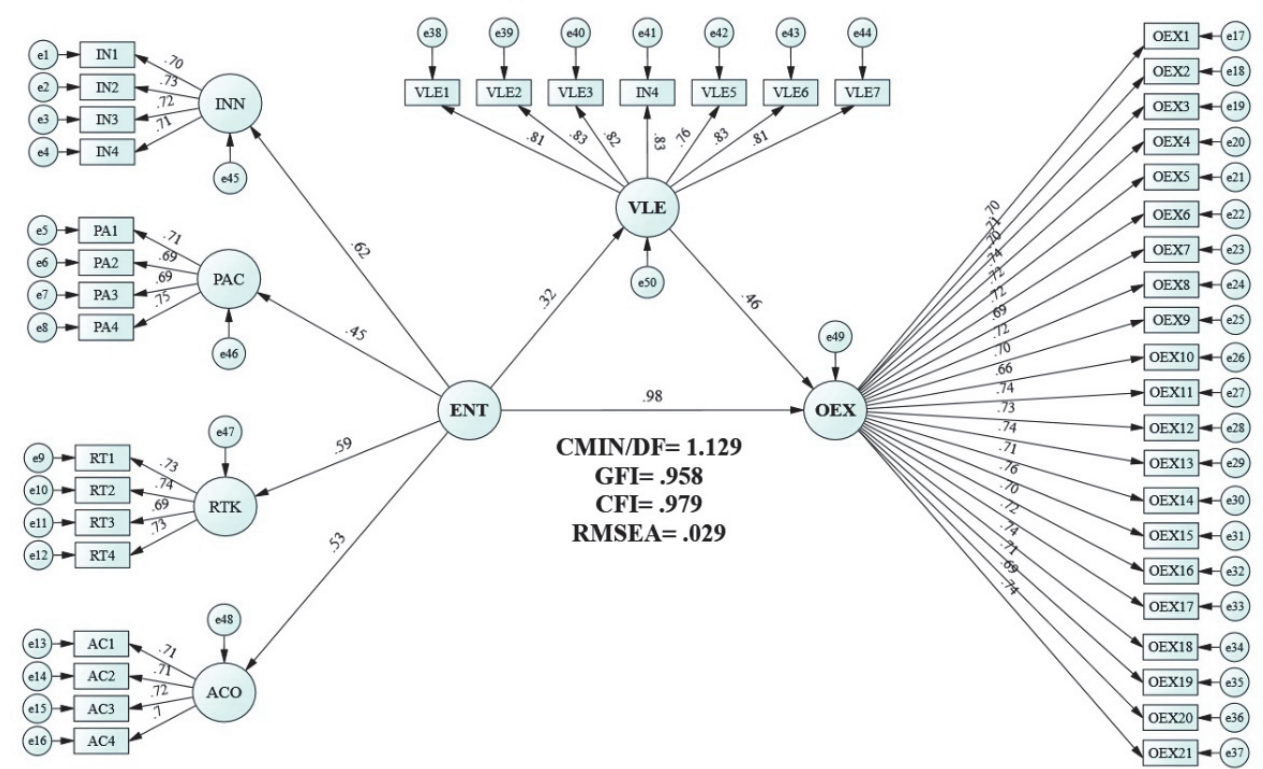

Fig. 4. Structural equation modeling to test the mediating impact of visionary leadership between entrepreneurship and organizational excellence.

Fig. 4 demonstrates that all values of the goodness of fit indicators were within the acceptance limits, where the ratio of (CMIN/DF) was (2.129) which is less than 3, and the values of (GFI) and (CFI) were greater than 0.90, which represents the minimum acceptance value. while the value of (RMSEA) was (0.029) which is less than 0.05, thereby the structural model used is considered appropriate.

\section{Discussion}

In this study, researcher aimed to find out how entrepreneurship with its four sub dimensions: risk taking, Innovativeness, Pro-activeness, and intensive competing; affects organizational excellence. This study claims that entrepreneurship is essential for today's businesses and economies that need extra-ordinary ideas and pro-activeness in very rapid and unexpected sever competing environment. The study adds depth to the effect of entrepreneurship by taking into consideration internal environment by consideration of visionary leadership. Building space and freedom for entrepreneurship has become a priority in our organizations. Being successful in global competing environment is not enough to sustain and most organizations need to reach excellence in all blocks that consist organization either explicitly or implicitly. Theoretical literature on entrepreneurship reflects that the process of applying is critical, risky and needs critical thinking skills and innovation, which few of people have. From other side, support and readiness of management to take this risk does not always exist because in most cases creative destruction must occur to increase productivity since entrepreneurship cannot flourish in an over-regulated economy. In this research, entrepreneurship appeared as accelerator for structural and policy changes and leads for organizational excellence, which means to be distinguished. Organizational excellence gives the company qualitative, quantitative and longterm superiority over competitors in the market. Achieving of organizational excellence needs talented management and leadership that drive toward shifting from a focus on physical capital to a focus on intellectual capital, and a focus on quality of services, to focus on service excellence (Al-Lozi, Almomani \& Al-Hawary,2017)

\section{Conclusion}

From the findings of the study, it can be concluded that there is an effect of entrepreneurship on organizational excellence in commercial Jordanian banks. The major effect was on strategy followed by organizational culture, which support the deep effect of entrepreneurship where strategy change can be considered explicit change while culture is implicit change. Thus, both dimensions are important to build organizational excellence. 
From other side, the findings also were: there is an effect of entrepreneurship on visionary leadership, which leads to attain organizational excellence. Researcher concludes that external and internal environments can act as motivator for entrepreneurship and consequently for achieving organizational excellence through having visionary leadership and flexible structures and policies. In addition, environments can act as restrictions and obstacles for entrepreneurship if there is no supporting management and supporting strategies and policies.

\section{Limitations and direction for future research}

There are some limitations in this study. First, the data of the study were collected from one of the commercial banks of Jordan. Therefore, the generalizability of current findings to other industries or countries should require additional investigation. We recommend a future research to be conducted on the whole bank sector in Jordan. Second the study has been carried out in the banking sector, the result may be different if the study is conducted in other industries. Third, the study examined the visionary leadership as a mediate variable between entrepreneurship and organizational excellence, so future research may be conducted by examining innovation as a mediate variable between entrepreneurship and organizational excellence.

\section{References}

Ab Hamid, M. R., Sami, W., \& Mohmad Sidek, M. H. (2017). Discriminant validity assessment: Use of Fornell \& Larcker criterion versus HTMT Criterion. Journal of Physics: Conference Series, 890, 1-6.

Ahmad, S., Zulkurnain, N., \& Khairushalimi, F. (2016). Assessing the validity and reliability of a measurement model in structural equation modeling (SEM). British Journal of Mathematics \& Computer Science, 15(3), 1-8.

Akbar, R. (2016). An Investigation of Determinants Global Entrepreneurship: Multi-Country Panel Studies. DeReMa Jurnal Manajemen, 11(1), 1-14.

Al-Hawary, S. I. S., \& Al-Namlan, A. A. (2018). Impact of electronic human resources management on the organizational learning at the private hospitals in the Sate of Qatar. Global Journal of Management and Business Research: A Administration and Management, 18(7), 1-11.

Al-Hawary, S. I. S., Batayneh, A. M. I., Mohammad, A. A. S., \& Alsarahni, A. H. H. (2017). Supply chain flexibility aspects and their impact on customers satisfaction of pharmaceutical industry in Jordan. International Journal of Business Performance and Supply Chain Modelling, 9(4), 326-343.

Al-Lozi, Musa Salameh, Almomani, Reham Zuhier Qasim and Al-Hawary, Sulieman Ibraheem Shelash (2017). Impact of talent management on achieving organizational excellence in Arab potash company in Jordan. Global Journal of Management and Business Research: A Administration and Management,17(7), 15-25

Antonites, A. J., \& Nonyane-Mathebula, B. T. (2012). Engineers as entrepreneurs: Enterpeneurial orientation of engineers in South Africa. South African Journal of Industrial Engineering, 23(1), 1-17.

ASQ (2015). What is Organizational Excellence?. [online] Available at: <http://asq.org/learn- about-quality/organizationalexcellence/> [Accessed 24 November 2017].

Bedoya, M. A., Alzate, B. A., \& Giraldo, L. M. (2018). Corporate Entrepreneurship and Entrepreneurial Orientation: The Impact on Managing Capabilities for Innovation. 2018 Portland International Conference on Management of Engineering and Technology (PICMET), 1-7.

Best, R.J. (2004). Market-Based Management: Strategies for Growing Customer Value and Profitability, 3rd Edition, Prentice Hall: Upper Saddle River, NJ.

Dana, L.-P., \& Ratten, V. (2017). International entrepreneurship in resource-rich landlocked African countries. Journal of International Entrepreneurship, 15(4), 416-435.

Darling, R. J., \& Nurmi, R. (1995). Downsizing the multinational firm: Key variables for excellence. Leadership \& Organizational Development Journal,16(5), 22-28.

Das, S. R., \& Joshi, M. P. (2007). Process innovativeness in technology services organizations: Roles of differentiation strategy, operational autonomy and risk-taking propensity. Journal of Operations Management, 25(3), 643-660.

De Oliveira, M. J., Bernardes, R. C., Borini, F. M., \& De Oliveira, A. B. (2016). Impact of entrepreneurial orientation on strategic alliances and the role of top management. Revista de Administração de Empresas, 56(3), 315-329.

Dess, G.G., \& Lumpkin, G.T. (2001) Linking two dimensions of entrepreneurial orientation to firm performance: the moderating role of environment and industry lifecycle. Journal of Business Venturing, 16, 429-451.

Dhammika K. A. S. (2016). Visionary leadership and organizational commitment: The mediating effect of leader-member exchange (LMX). Wayamba Journal of Management, 4 (1), 1-10.

Dvouletý, O. (2017). Can policy makers count with positive impact of entrepreneurship on economic development of the Czech regions? Journal of Entrepreneurship in Emerging Economies, 9(3), 286-299.

Dzomonda, O., Fatoki, O., \& Oni, O. (2017). The impact of leadership styles on the entrepreneurial orientation of small and medium enterprises in South Africa. Journal of Economics and Behavioral Studies, 9(2(J)), 104-113.

Eggers, F., Kraus, S., Hughes, M., Laraway, S. and Syncerksi, S. (2013) Implications of customer and entrepreneurial orientations for SME growth. Management Decision, 51(3), 524-546.

Fornell, C., \& Larcker, D. (1981)., Evaluating structural equations models with unobservable variables and measurement error. Journal of Marketing Research 18(1), 39-50. 
Frederick, H., O’Connor, A., \& Kuratko, D. F. (2019). Entrepreneurship: Theory,process, and practice.

Gaddam, S. (2008). Identifying the relationship between behavioral motives and entrepreneurial intentions: An empirical study based on the perceptions of business management students. The Icfaian Journal of Management Research, 7(5), 3555.

Gathungu, J. M., Aiko, D. M., \& Machuki, V. N. (2014). Entrepeneurial orientation, networking, external environment, and firm performance: A critical literature review. European Scientific Journal, 10(7), 335-357.

Genc, E., Dayan, M., \& Genc, O. F. (2019). The impact of SME internationalization on innovation: The mediating role of market and entrepreneurial orientation. Industrial Marketing Management, 82, 253-264.

Golmohammadi, M., Ghorbani, A., \& Feyzi, M. (2016). The effect of job attitudes and organizational identity in organizational excellence of employees (Case Study: Staff of Department of Natural Resources and Watershed of Ardabil province). International Journal of Humanities and Cultural Studies (IJHCS) ISSN 2356-5926, 1(1), 1281-1288.

Hadi, A. A., Abdullah, H., \& Atshan, N. (2019). Effect of organisational integrity and leadership behaviour on organisational excellence. International Journal of Organizational Analysis, 27(4), 972-985.

Haider, S. H., Asad, M., \& Fatima, M. (2017). Entrepreneurial Orientation and Business Performance of Manufacturing Sector Small and Medium Scale Enterprises of Punjab Pakistan. European Business \& Management, 3(2), $21-28$.

Hair, J. F., Hult, G. T. M., Ringle, C. M., \& Sarstedt, M. (2017). A primer on partial least squares structural equation modeling (PLS-SEM) (Second edition). SAGE.

Karim, M. S. A. (2016). Entrepreneurship Education in an Engineering Curriculum. Procedia Economics and Finance, 35, 379-387.

Kearney, E., Shemla, M., van Knippenberg, D., \& Scholz, F. A. (2019). A paradox perspective on the interactive effects of visionary and empowering leadership. Organizational Behavior and Human Decision Processes, 155, 20-30.

Kotler, P. (2003). A Framework for Marketing Management, 3rd Edition, Prentice Hall: Upper Saddle River, NJ.

Mahalli, A. (2013). Applying the EFQM model in performance measuring of organization: Department of Management, Islamic Azad University, Iran. Standard Research Journal of Business Management, 1(1), 41-51.

Northouse, P.G. (2013), Leadership Theory and Practice, 6th ed., Sage publications, CA.

Nunnally, J. C., \& Bernstein, I. H. (1994). The theory of measurement error. Psychometric Theory, 3, 209-247.

Olannye, A. P., \& Eromafuru, E. (2016). The dimension of entrepreneurial marketing on the performance of fast food restaurants in Asaba, Delta State, Nigeria. Journal of Emerging Trends in Economics and Management Sciences, 7(3), $137-146$.

Park, J. (2017). Tolerance intervals from ridge regression in the presence of multicollinearity and high dimension. Statistics \& Probability Letters, 121, 128-135.

Salamzadeh, A., Tajpour, M., \& Hosseini, E. (2019). Corporate entrepreneurship in University of Tehran: Does human resources management matter. International Journal of Knowledge-Based Development, 10(3), 276.

Samawi, G. A., Abu-Tayeh, B. K., Yosef, F., Madanat, M., \& Al-Qatawneh, M. I. (2018). Relation between total quality management practices and business excellence: evidence from private service firms in Jordan. International Review of Management and Marketing, 8(1), 28-35.

Shelton, C. D., J., \& Walker, W. (2002). Foundations of organizational excellence. Leadership Values, Strategies and Skills LTA, 1(2), 46-63.

Shepherd, D. A., \& Wiklund, J. (2020). Simple rules, templates, and heuristics! An attempt to deconstruct the craft of writing an entrepreneurship Paper. Entrepreneurship Theory and Practice, 44(3), 371-390.

Shi, D., Lee, T., \& Maydeu-Olivares, A. (2019). Understanding the model size effect on SEM Fit Indices. Educational and Psychological Measurement, 79(2), 310-334.

Sozuer, A., Altuntas, G., \& Semercioz, F. (2017). International entrepreneurship of small firms and their export market performance. European Journal of International Management, 11(3), 365.

Sung, K.-S., Yi, Y. G., \& Shin, H.-I. (2019). Reliability and validity of knee extensor strength measurements using a portable dynamometer anchoring system in a supine position. BMC Musculoskeletal Disorders, 20(1), 1-8.

Taylor, C. M., Cornelius, C. J. \& Colvin, K. (2013). Visionary leadership and its relationship to organizational effectiveness. Leadership \& Organization Development Journal, 35(6), 566-583.

Thompson, C. G., Kim, R. S., Aloe, A. M., \& Becker, B. J. (2017). Extracting the variance inflation factor and other multicollinearity diagnostics from typical regression results. Basic and Applied Social Psychology, 39(2), 81-90.

Webster, M., (2016). Organizational Excellence. So what is organizational excellence.

Wing, R.L. (1988). The Art of Strategy: A New Translation of Sun Tzu's Classic the Art of War, New York: Doubleday.

Xaba, M., \& Malindi, M. (2010). Entrepreneurial orientation and practice: Three case examples of historically disadvantaged primary schools. South African Journal of Education, 30(1), 75-89.

Zenk, S. N., Kraft, A. N., Jones, K. K., \& Matthews, S. A. (2019). Convergent validity of an activity-space survey for use in health research. Health \& Place, 56, 19-23.

Zhou, L., Zhao, S., Tian, F., Zhang, X., \& Chen, S. (2018). Visionary leadership and employee creativity in China. International Journal of Manpower. 39(1), 93-105.

Zhu, W., Chew, I. K., \& Spangler, W. D. (2005). CEO transformational leadership and organizational outcomes: The mediating role of human-capital-enhancing human resource management. The Leadership Quarterly, 16(1), 39-52. 
(C) 2020 by the authors; licensee Growing Science, Canada. This is an open access article distributed under the terms and conditions of the Creative Commons Attribution (CC-BY) license (http://creativecommons.org/licenses/by/4.0/). 